\title{
Characterization of Waste Material Derived Willemite-Based Glass-Ceramics Doped with Erbium
}

\author{
G. V. Sarrigani, ${ }^{1,2}$ H. J. Quah, ${ }^{3}$ W. F. Lim, ${ }^{1}$ K. A. Matori, ${ }^{1,2}$ \\ N. S. Mohd Razali, ${ }^{2}$ A. Kharazmi, ${ }^{2}$ M. Hashim, ${ }^{1,2}$ and H. R. Bahari ${ }^{4}$ \\ ${ }^{1}$ Materials Synthesis and Characterization Laboratory, Institute of Advanced Technology, Universiti Putra Malaysia, \\ 43400 Serdang, Selangor, Malaysia \\ ${ }^{2}$ Department of Physics, Faculty of Science, Universiti Putra Malaysia (UPM), 43400 Serdang, Selangor, Malaysia \\ ${ }^{3}$ Materials Processing and Technology Laboratory, Institute of Advanced Technology, Universiti Putra Malaysia, \\ 43400 Serdang, Selangor, Malaysia \\ ${ }^{4}$ Institute of Microengineering and Nanoelectronics (IMEN), Level 4, Research Complex, Universiti Kebangsaan Malaysia, \\ 43600 Bangi, Selangor, Malaysia
}

Correspondence should be addressed to K. A. Matori; khamirul@upm.edu.my

Received 26 February 2015; Revised 26 May 2015; Accepted 1 June 2015

Academic Editor: Peter Majewski

Copyright (C) 2015 G. V. Sarrigani et al. This is an open access article distributed under the Creative Commons Attribution License, which permits unrestricted use, distribution, and reproduction in any medium, provided the original work is properly cited.

\begin{abstract}
We reported, for the first time, to the best of our knowledge, the production of erbium doped willemite-based glass-ceramic using waste material. In this work, a willemite-based glass-ceramic was prepared from waste material to obtain excellent crystallinity and then doped with trivalent erbium $\left(\mathrm{Er}^{3+}\right)$ to yield $\left(\left[(\mathrm{ZnO})_{0.5}(\mathrm{SLS})_{0.5}\right]_{1-x}\left[\mathrm{Er}_{2} \mathrm{O}_{3}\right]_{x}\right)$ final composition where $x=3 \mathrm{wt} \%$. The samples were sintered at various temperatures $\left(500-1100^{\circ} \mathrm{C}\right)$ to study the effects of sintering temperatures on microstructure and physical properties of the samples. X-ray diffraction (XRD) and Fourier transform infrared (FTIR) were used to determine structural changes and functional groups in the samples, respectively. Field-emission scanning electron microscopy (FE-SEM) equipped with energy dispersive X-ray was used to observe surface morphology and to detect presence of elements in the samples. Findings showed that average grain size of the $\mathrm{Er}^{3+}$ doped glass-ceramic sample increased as a function of the sintering temperature and the optimum temperature was $900^{\circ} \mathrm{C}$.
\end{abstract}

\section{Introduction}

In recent years, glass-ceramics doped with rare-earth ions have attracted significant attention because of their wide application in the field of laser technology and optical communications [1]. Thus far, various glass-ceramics (silicates and phosphates) have been utilized as the proper hosts for the rare-earths. However, poor chemical stability and low transition temperature of phosphates have restricted the use of phosphates as the host for these ions [2]. In contrast, silicates demonstrate much superior chemical stability when compared with the phosphates and therefore were advantageous for ion-exchange technique to produce optical waveguides [2]. In addition, silicate materials are more economic due to the traditional technology used for telecommunication application. Recently, different rare-earth ions have been studied as dopants in silicate-based glass-ceramics [3-5]. Among the doped materials, erbium oxide $\left(\mathrm{Er}_{2} \mathrm{O}_{3}\right)$ is one of the promising materials for the use as a dopant in the silicatebased glass ceramics. Besides being a rare-earth oxide, it was anticipated that $\mathrm{Er}_{2} \mathrm{O}_{3}$ is unique due to the existence of trivalent charge $\left(\mathrm{Er}^{3+}\right)$ on the cation, which may lead to the formation of active site for the charge transfer, eventually causing a transition of the absorption bands from $4 \mathrm{f}^{4} \mathrm{I}_{13 / 2}$ to ${ }^{4} \mathrm{I}_{15 / 2}$ [1]. The anticipation provoked, having known that the unique feature found in the rare-earth cerium oxide $\left(\mathrm{CeO}_{2}\right)$ was attributed to the existence of $\mathrm{Ce}^{3+}$ in the oxide as a result of phase transition from $\mathrm{Ce}^{4+}$ to $\mathrm{Ce}^{3+}[6,7]$. This property has brought wide applications of the $\mathrm{CeO}_{2}$ not only as an optical material but also as a high dielectric constant gate oxide used 
in metal-oxide-semiconductor based devices $[8,9]$. To date, the $\mathrm{Er}^{3+}$-doped silicate has been widely used in developing elements and sources for telecommunication systems since the wavelength region for telecommunications, which is around $1500 \mathrm{~nm}$, coincides with the inter- $4 \mathrm{f}{ }^{4} \mathrm{I}_{13 / 2} \rightarrow{ }^{4} \mathrm{I}_{15 / 2}$ transition of $\mathrm{Er}^{3+}$ ion at $1535 \mathrm{~nm}$ [1].

Amongst the silicate-based glass ceramics, willemite has attained considerable attention over the last 180 years as the zinc silicate material. Following its discovery, interest in the zinc silicate was focused toward its occurrence, crystallography, and application as an industrial material [1]. In addition, glass-ceramics are typically obtained by heat treatment of glassy precursors or by sintering green bodies consisting of glassy and crystalline materials [10,11]. A number of literatures have been reporting on the preparation of $\mathrm{Er}^{3+}$ :SLS (Soda Lime Silicate) glass and zinc silicate composites. Kaewwiset et al. [12] reported the preparation of $\mathrm{Er}_{2} \mathrm{O}_{3}$ doped SLS glass using a solid-state reaction at $1200^{\circ} \mathrm{C}$. In another study, Cho and Chang [13] used similar solidstate reaction at $1400^{\circ} \mathrm{C}$ to produce manganese-doped zinc silicate green phosphor with appropriate oxides. To the best of our knowledge, despite extensive researches on producing willemite glass-ceramics, doped with rare-earths and metals using pure materials $[14,15]$, there is no report regarding the doping of $\mathrm{Er}^{3+}$ into willemite, which is produced from waste material. Therefore, it is of interest to investigate in present study for the production of willemite-based glass ceramics from waste material before being doped with $3 \mathrm{wt} \%$ of $\mathrm{Er}^{3+}$ by systematically studying the effects of various sintering temperatures on structural, chemical, and morphological properties of prepared samples.

\section{Experimental}

2.1. Materials. Willemite-based glass-ceramics doped with $\mathrm{Er}^{3+}\left(\mathrm{Zn}_{2} \mathrm{SiO}_{4}: \mathrm{Er}^{3+}\right)$ were prepared using the following materials: high purity $\mathrm{ZnO}$ (99.99\%, Aldrich), $\mathrm{Er}_{2} \mathrm{O}_{3}$ (99.99\%, Aldrich), and SLS glass waste bottle.

2.2. Preparation. First, SLS glass bottles were cleaned and crushed properly to $<63 \mu \mathrm{m}$ using a mortar and pestle. Then, the SLS glass and $\mathrm{ZnO}$ powders were carefully mixed at a weight ratio of $1: 1$ during a ball milling process for $24 \mathrm{~h}$. The mixture powder was afterward put in an alumina crucible and melted in an electric furnace at $1400^{\circ} \mathrm{C}$ for $4 \mathrm{~h}$ in air environment. Subsequently, the samples were quenched immediately into water in order to gain glass frit. The frit was again ground to $<63 \mu \mathrm{m}$ particles followed by a heat treatment at $1000^{\circ} \mathrm{C}$ in order to produce the willemite glassceramics. Unlike previous techniques of doping rare-earths [16], in this work $3 \mathrm{wt} \%$ of $\mathrm{Er}_{2} \mathrm{O}_{3}$ was doped in the last stage whereby the willemite had fully crystallized in the glassceramics. The mixing happened in a mortar and pestle for $1 \mathrm{~h}$, followed by ball milling for the next $24 \mathrm{~h}$. The obtained powder was pressed to pellets with $12 \mathrm{~mm}$ diameter and subsequently sintered at different temperatures $\left(500-1100^{\circ} \mathrm{C}\right)$ for $4 \mathrm{~h}$ at a heating and cooling rate of $10^{\circ} \mathrm{C} / \mathrm{min}$.

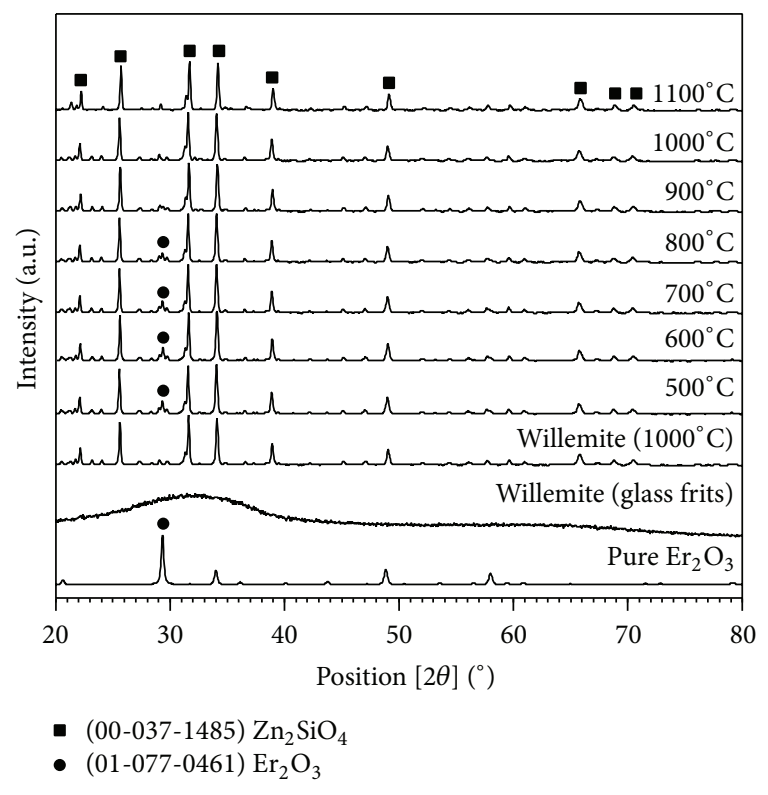

FIGURE 1: The XRD patterns of the willemite-based glass-ceramic $\left(\mathrm{Zn}_{2} \mathrm{SiO}_{4}\right)$ sample doped with $3 \mathrm{wt} \% \mathrm{Er}_{2} \mathrm{O}_{3}$ sintered at the temperature of $500-1100^{\circ} \mathrm{C}$ for $4 \mathrm{~h}$.

2.3. Characterization. X-ray diffraction (XRD) analysis was performed by X-ray diffractometer (PANAalytical (Philips) X'Pert Pro PW3050/60) with $\mathrm{CuK} \alpha$ radiation (Bragg angle $2 \theta$ in the angular range of 20 to $80^{\circ}$ ) equipped with a copper $\mathrm{X}$-ray tube and scintillation detector. To identify crystalline phases in the analyzed samples, the powder diffraction file (PDF2) was used. Fourier transform infrared (FTIR) spectra of the samples were recorded over the range of $0-4000 \mathrm{~cm}^{-1}$ on a Perkin-Elmer 1752X spectrophotometer (Waltham, MA) using a $\mathrm{KBr}$ disc method. In order to obtain good quality FTIR spectra, the samples were crushed in an agate mortar to obtain fine powder. Microstructural observations were performed using a field-emission scanning electron microscopy (FESEM) modelled FEI NOVA NanoSEM 230 and equipped with energy dispersive X-ray (EDX) spectrometer. Finally, grain size of the samples was measured using mean linear intercept method.

\section{Results and Discussion}

3.1. Structural Studies. XRD patterns of $\mathrm{Zn}_{2} \mathrm{SiO}_{4}: \mathrm{Er}_{2} \mathrm{O}_{3}$ samples sintered at different temperatures ranging from 500 to $1100^{\circ} \mathrm{C}$ for $4 \mathrm{~h}$ are discretely presented in Figure 1 . The first XRD pattern (the most bottom pattern in Figure 1) shows diffraction peaks detected for pure erbium oxide $\left(\mathrm{Er}_{2} \mathrm{O}_{3}\right)$, followed by the second pattern for glass frits and the third pattern for unsintered and undoped willemitebased glass-ceramics. It was observed that main diffraction peak of erbium oxide $\left(\mathrm{Er}_{2} \mathrm{O}_{3}\right)$ was located at diffraction angles $(2 \theta)$ of $29.29^{\circ}$ while the XRD pattern shown for glass frits indicated amorphous nature of the glass frits. In the willemite sample sintered at $1000^{\circ} \mathrm{C}$ shown in the third XRD pattern, diffraction peaks detected at $2 \theta$ of $22.14^{\circ}, 25.61^{\circ}$, 
TABLE 1: FTIR transmission features and their assignments for oxide $\left[(\mathrm{ZnO})_{0.5}(\mathrm{SLS})_{0.5}\right]_{1-x}\left[\mathrm{Er}_{2} \mathrm{O}_{3}\right]_{x}$ system.

\begin{tabular}{lc}
\hline $\begin{array}{l}\text { Wavenumber } \\
{\left[\mathrm{cm}^{-1}\right]}\end{array}$ & Assignment \\
\hline 395 & Asymmetric deformation stretching of $\mathrm{SiO}_{4}\left(v_{4} \mathrm{SiO}_{4}\right)$ \\
485 & Asymmetric stretching of $\mathrm{SiO}_{4}\left(v_{3} \mathrm{SiO}_{4}\right)$ \\
595 & Asymmetric stretching of $\mathrm{ZnO}_{4}\left(v_{3} \mathrm{ZnO}_{4}\right)$ \\
702 & Totally symmetric stretching of $\mathrm{SiO}_{4}\left(v_{1} \mathrm{SiO}_{4}\right)$ \\
902 & Asymmetric stretching of $\mathrm{SiO}_{4}\left(v_{3} \mathrm{SiO}_{4}\right)$ \\
\hline
\end{tabular}

$31.61^{\circ}, 38.90^{\circ}, 49.01^{\circ}$, and $65.87^{\circ}$, respectively, corresponded to the crystalline planes of (3 $\left.\begin{array}{lll}3 & 0\end{array}\right),\left(\begin{array}{lll}2 & 2 & 0\end{array}\right),\left(\begin{array}{lll}1 & 1 & 3\end{array}\right),\left(\begin{array}{ll}4 & 1\end{array}\right.$ $0)$, ( $\left.\begin{array}{lll}2 & 2 & 3\end{array}\right),\left(\begin{array}{lll}3 & 3 & 3\end{array}\right)$, and (2 26 ). The results agreed well with the findings from previous researchers [17-20], wherein rhombohedral crystalline phase of willemite was formed after the mixing of $\mathrm{ZnO}$ and SLS glass followed by a heat treatment at $1000^{\circ} \mathrm{C}$ [20]. By doping with $3 \mathrm{wt} \%$ of $\mathrm{Er}_{2} \mathrm{O}_{3}$ into the willemite and sintering at $500^{\circ} \mathrm{C}$, an additional peak, ascribed to (222) diffraction plane of cubic crystalline phase of $\operatorname{Er}_{2} \mathrm{O}_{3}$, appeared at $2 \theta=29.29^{\circ}$. The detection of single diffraction peak associated with $\mathrm{Er}_{2} \mathrm{O}_{3}$ indicated that the $\mathrm{Er}_{2} \mathrm{O}_{3}$ did not react with the crystalline $\mathrm{Zn}_{2} \mathrm{SiO}_{4}$ and therefore remained as an unreacted phase at $500^{\circ} \mathrm{C}$. As the sintering temperature was increased from 500 to $700^{\circ} \mathrm{C}$, the intensity decreased gently with a dramatic fall when temperature reached $800^{\circ} \mathrm{C}$. Beyond $900^{\circ} \mathrm{C}$, it was seen that the diffraction peak of crystalline $\mathrm{Er}_{2} \mathrm{O}_{3}$ started to diminish, leaving only the main diffraction peaks attributed to the willemite. The occurrence of this might be due to a complete entering of the $\mathrm{Er}^{3+}$ cations into the $\mathrm{Zn}_{2} \mathrm{SiO}_{4}$ lattice. Phase formation of the willemitebased glass-ceramics was further confirmed using FTIR.

3.2. FTIR Analysis. FTIR spectroscopy was performed to obtain fundamental information concerning the functional groups of the studied glass-ceramics. FTIR spectra of the willemite-based glass-ceramics with the content of $3 \mathrm{wt} \%$ $\mathrm{Er}_{2} \mathrm{O}_{3}$ sintered at different temperatures are presented in Figure 2. The bands detected in the FTIR spectra have been summarized in Table 1. The experimental data gained in present work were compared with those of some related vitreous and crystalline compounds [21-25]. It was deduced that the FTIR spectra of glass-ceramic matrix $\left(\mathrm{Zn}_{2} \mathrm{SiO}_{4}: \mathrm{Er}_{2} \mathrm{O}_{3}\right)$ consisted of eight wide and strong transmission bands, positioned at $395 \mathrm{~cm}^{-1}, 485 \mathrm{~cm}^{-1}, 595 \mathrm{~cm}^{-1}, 702 \mathrm{~cm}^{-1}$, and $902 \mathrm{~cm}^{-1}$. Normally, the metal-oxide vibrations would occur below $1000 \mathrm{~cm}^{-1}$. The transmission peak in the lower wave number of $395 \mathrm{~cm}^{-1}$ was assigned to the asymmetric deformation of $\mathrm{SiO}_{4}$ group $\left(v_{4} \mathrm{SiO}_{4}\right)$ [26]. The band positioned at $485 \mathrm{~cm}^{-1}$ corresponded to $\mathrm{SiO}_{4}$ asymmetric stretching vibration $\left(\nu_{3} \mathrm{SiO}_{4}\right)[27,28]$. The peak at $595 \mathrm{~cm}^{-1}$ was marked as the asymmetric stretching vibration of $\mathrm{ZnO}_{4}$ group $\left(v_{3}\right.$ $\mathrm{ZnO}_{4}$ ) [29-33]. The distinct band placed at $702 \mathrm{~cm}^{-1}$ could be assigned as the totally symmetric stretching vibration of $\mathrm{SiO}_{4}$ group $\left(\nu_{1} \mathrm{SiO}_{4}\right)$ [34-36]. The broad band located at $902 \mathrm{~cm}^{-1}$ corresponded to asymmetric stretching of $\mathrm{SiO}_{4}\left(\nu_{3} \mathrm{SiO}_{4}\right)$ [17].

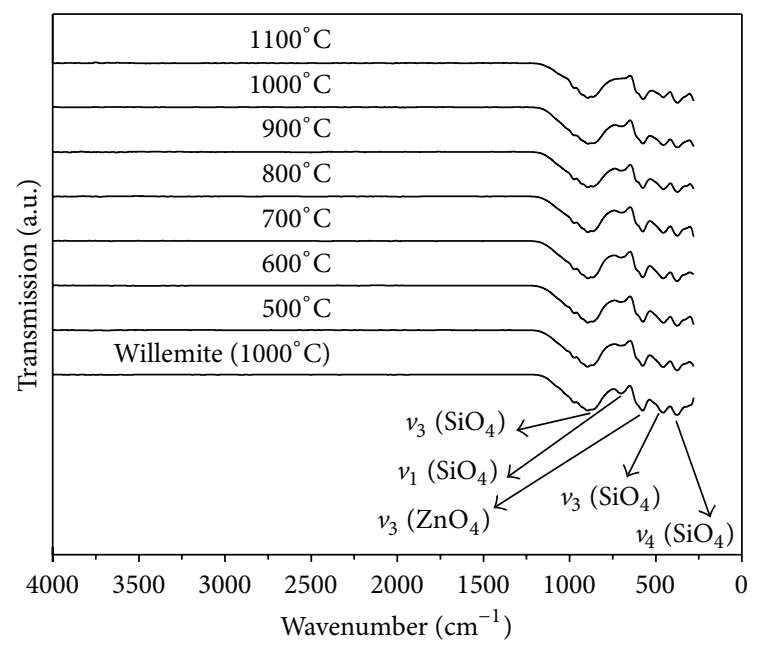

FIGURE 2: FTIR spectra of the willemite-based glass-ceramic samples doped with $3 \mathrm{wt} \% \mathrm{Er}_{2} \mathrm{O}_{3}$ sintered at the temperature of 500$1100^{\circ} \mathrm{C}$ for $4 \mathrm{~h}$.

As a whole, the presence of vibrations associated with $\mathrm{SiO}_{4}$ and $\mathrm{ZnO}_{4}$ groups would clearly suggest the formation of $\mathrm{Zn}_{2} \mathrm{SiO}_{4}$ phase [37]. The increase of sintering temperature from 500 to $1100^{\circ} \mathrm{C}$ would cause an increase in intensities of the FTIR bands. On the other hand, at higher temperature of $1100^{\circ} \mathrm{C}$, the band situated at $700 \mathrm{~cm}^{-1}$ disappeared. A compositional evaluation of the FTIR properties of the $\left[(\mathrm{ZnO})_{0.5}(\mathrm{SLS})_{0.5}\right]_{1-x}\left[\mathrm{Er}_{2} \mathrm{O}_{3}\right]_{x}$ system in present work proposed that the presence of $\mathrm{Er}^{3+}$ ions would affect the surroundings of $\mathrm{Si}-\mathrm{O}$ bond and the trivalent $\mathrm{Er}^{3+}$ would occupy the position. The literature reported that FTIR spectrum of crystalline (cubic) $\mathrm{Er}_{2} \mathrm{O}_{3}$ would show characteristic transmission bands located at $469 \mathrm{~cm}^{-1}$, assigned to the Er$O$ bond vibrations [38]. Hence, the band located at $469 \mathrm{~cm}^{-1}$ would belong to the vibrations of the Er-O group present in the studied glass-ceramic system. In addition, the most significant modification produced by the addition of $\mathrm{Er}^{3+}$ and the increase of sintering temperature of the studied samples was related with a drop in intensity of the FTIR band located at $702 \mathrm{~cm}^{-1}$. Results indicated that the addition of $\mathrm{Er}_{2} \mathrm{O}_{3}$ into willemite as well as the increase of sintering temperature had led to a reduction in the content of $\mathrm{SiO}_{4}$ group.

3.3. Surface Morphological Analysis. Figures 3(a)-3(f) show FESEM images of the willemite-based glass ceramics doped with of $3 \mathrm{wt} \%$ of $\mathrm{Er}^{3+}$ as a function of sintering temperature $\left(500-1000^{\circ} \mathrm{C}\right.$ ) (Figures $3(\mathrm{~b})-3(\mathrm{f})$ ) in comparison with the willemite glass ceramic without the doping (Figure 3(a)). As it can be observed in Figure 3(a), the crystallized particles aggregated and were irregular in shape. In addition, the willemite surface showed a homogenous distribution of rhombohedral-like particles. By observing Figure 3(b), it could be seen that when the willemite was doped with $3 \mathrm{wt} \%$ of $\mathrm{Er}^{3+}$ and sintered at the temperatures of $700^{\circ} \mathrm{C}$, the $\mathrm{Er}^{3+}$ ions were dispersed on surface of the willemite and did not contribute to the ceramic's lattice. On the other hand, 


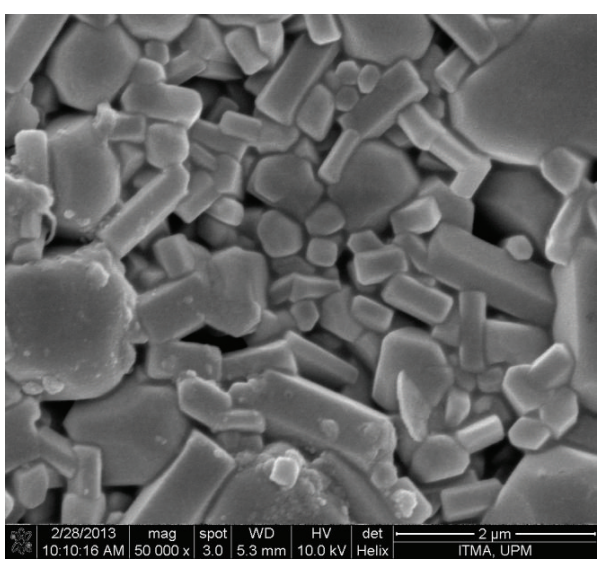

(a)

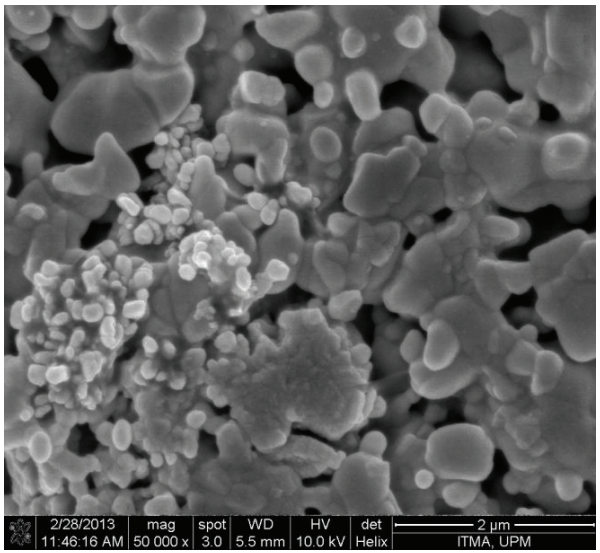

(c)

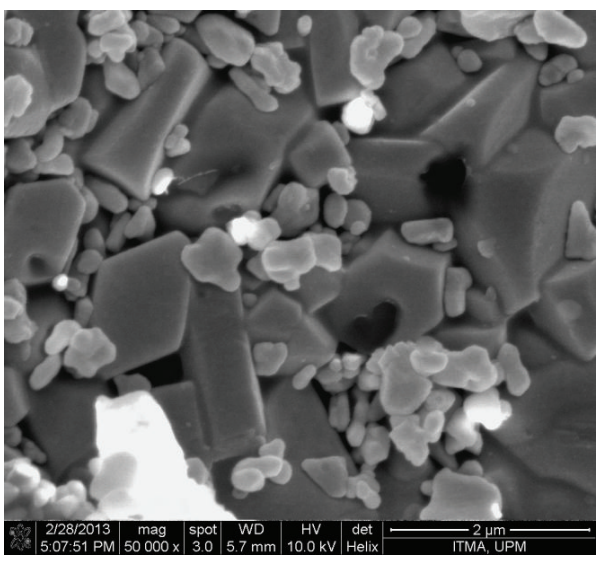

(e)

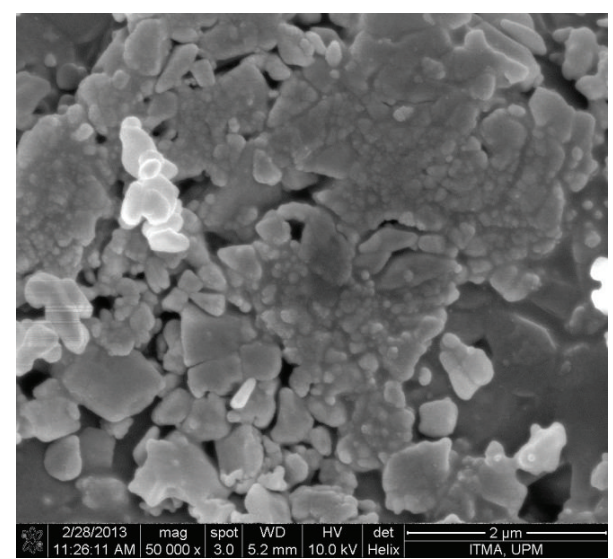

(b)

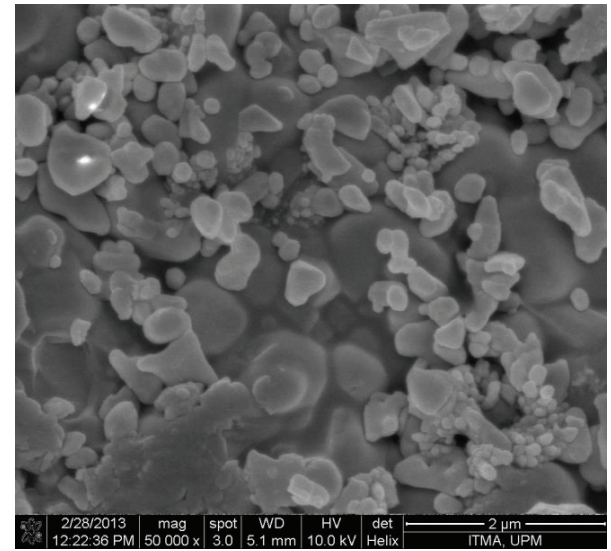

(d)

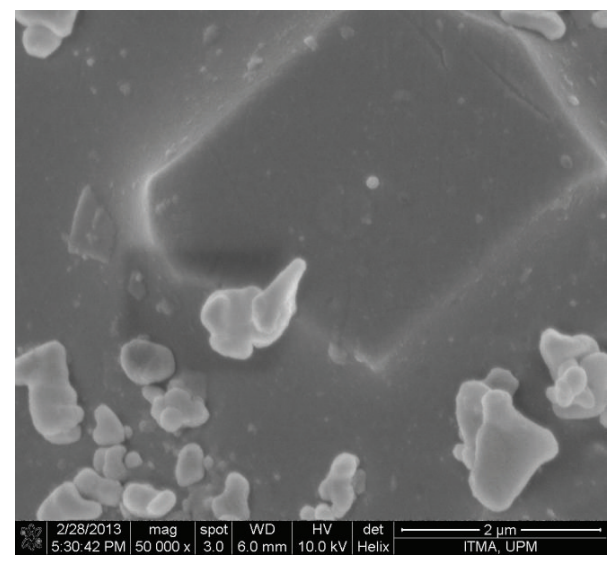

(f)

FIGURE 3: FESEM micrographs of willemite and $\mathrm{Er}^{3+}$ doped glass-ceramic pellets sintered $4 \mathrm{~h}$ at different temperatures: (a) willemite, (b) $700^{\circ} \mathrm{C}$, (c) $800^{\circ} \mathrm{C}$, (d) $900^{\circ} \mathrm{C}$, (e) $1000^{\circ} \mathrm{C}$, and (f) $1100^{\circ} \mathrm{C}$.

after increasing the sintering temperature up to $800^{\circ} \mathrm{C}$ and $900^{\circ} \mathrm{C}$ (Figures 3(c) and 3(d)), surface morphology of the impact powder became granular and appeared to have a homogenous distribution, which could be due to a reaction of the $\mathrm{Er}^{3+}$ with the willemite. However, agglomeration of the willemite occurred while approaching the temperature of $1000^{\circ} \mathrm{C}$ (Figure 3(e)) whereby the clustered $\mathrm{Er}^{3+}$ remained on the surface. Subsequently, at the temperature of $1100^{\circ} \mathrm{C}$ (Figure 3(f)), the willemite melted and had completely covered the dopant particles. As a conclusion, it could be said that the amorphous phase was reduced during sintering. In addition, as the temperature was increased to $1000^{\circ} \mathrm{C}$, less grain boundaries were present due to grain growth. However, at the temperature of $1100^{\circ} \mathrm{C}$, it was impossible to 


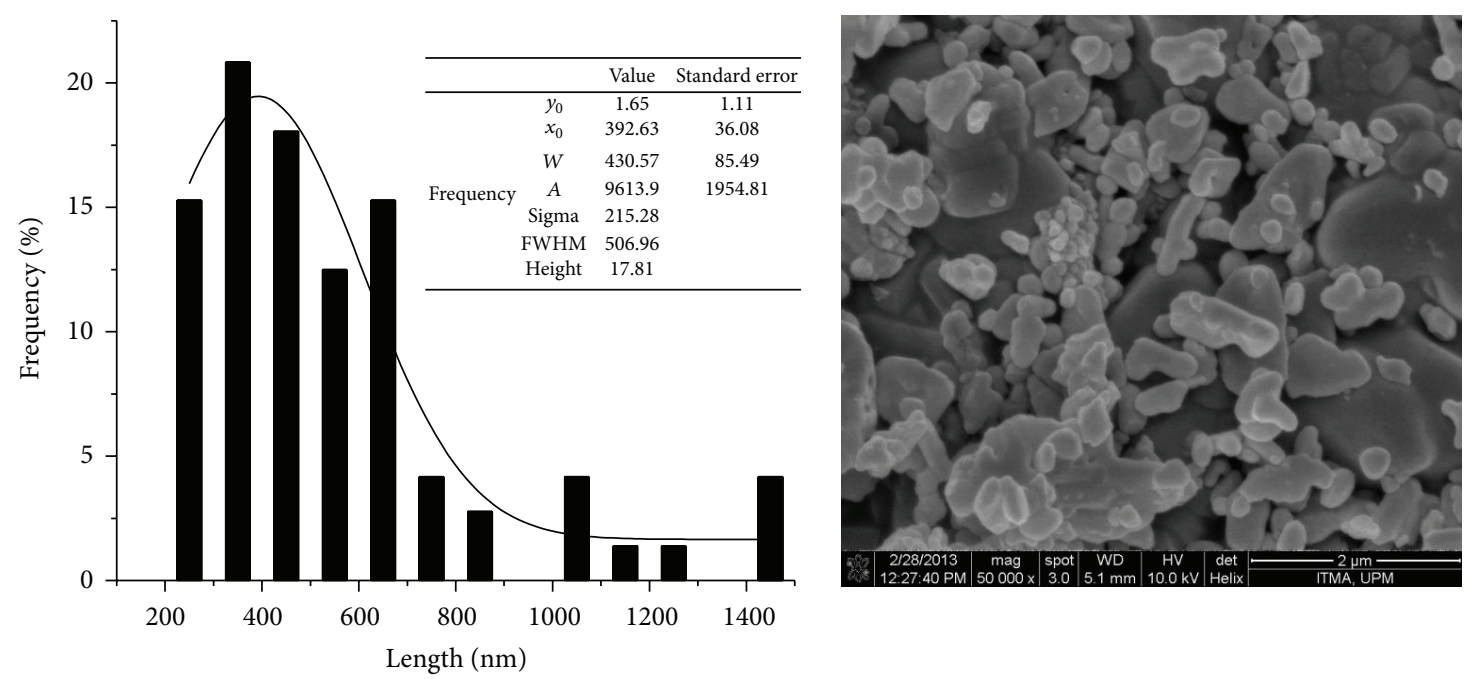

FIGURE 4: Grain size distribution of $3 \mathrm{wt} \% \mathrm{Er}^{3+}$ doped willemite-based glass-ceramic crystals in the glass-ceramic samples sintered at $900^{\circ} \mathrm{C}$ for $4 \mathrm{~h}$.
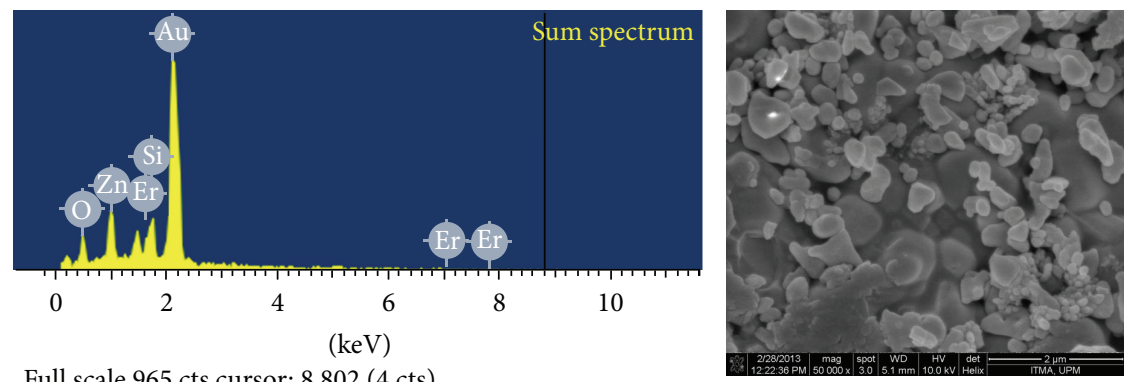

FIGURE 5: FESEM-EDX analysis of the distribution of $\mathrm{Er}^{3+}$ in the willemite-based glass-ceramic doped with 3 wt $\% \mathrm{Er}^{3+}$ and sintered at the temperature of $900^{\circ} \mathrm{C}$.

calculate grain size of the sample due to the melting process. A summary of the obtained grain sizes of the samples has been presented in Figure 4. The distribution of $\mathrm{Er}^{3+}$ in the willemite matrix was confirmed by FESEM-EDX analysis, as shown in Figure 5. The EDX spectrum distinctly showed the presence of $\mathrm{Zn}, \mathrm{O}, \mathrm{Si}, \mathrm{Al}$, and Er, in addition to the $\mathrm{Au}$ peak, resulting from the sputtered gold on the surface during the characterization process. However, the detection of $\mathrm{Al}$ peak was due to the SLS glass from the waste material. The sintering temperature was at or above $1200^{\circ} \mathrm{C}[39,40]$ in most of the recently reported investigations; however, it had been decreased to a lower temperature $\left(900^{\circ} \mathrm{C}\right)$ in the present work. In addition, other impurities, such as ferum and ferum oxide were not detected for all of the investigated samples.

\section{Conclusions}

Structural changes induced by sintering temperature in the willemite-based glass-ceramic doped with trivalent erbium ions were well reflected in X-ray diffraction patterns, FTIR spectra, and FESEM images. Sintering of the samples produced homogeneity. The presence of willemite and $\mathrm{Er}^{3+}$ was being evidenced by X-ray diffraction analysis. The FTIR data suggested the presence of $\mathrm{SiO}_{4}, \mathrm{ZnO}_{4}$, and Er-O structural units. The microstructural study proposed that, by increasing the sintering temperature, the grain size increased. One of the most dominant results of this work was regarding the sintering of the synthesized pellets at a relatively lower temperature $\left(900^{\circ} \mathrm{C}\right)$, which resulted in the formation of polycrystalline erbium-doped willemite samples. The structural properties of synthesized samples were comparable with previously reported materials.

\section{Conflict of Interests}

The authors declare that they have no conflict of interests.

\section{Acknowledgments}

The researchers gratefully acknowledge the financial support for this study from the Malaysian Ministry of Higher Education (MOHE) through the Fundamental Research Grant Scheme. The authors (H. J. Quah and W. F. Lim) would like to thank the financial support from the Universiti Putra Malaysia Post-Doctoral Fellowship. 


\section{References}

[1] A. J. Kenyon, "Recent developments in rare-earth doped materials for optoelectronics," Progress in Quantum Electronics, vol. 26, no. 4-5, pp. 225-284, 2002.

[2] P. Capek, M. Mika, J. Oswald et al., "Effect of divalent cations on properties of $\mathrm{Er}^{3+}$-doped silicate glasses," Optical Materials, vol. 27, no. 2, pp. 331-336, 2004.

[3] Z. Pan, K. James, Y. Cui et al., "Terbium-activated lithiumlanthanum-aluminosilicate oxyfluoride scintillating glass and glass-ceramic," Nuclear Instruments and Methods in Physics Research, Section A: Accelerators, Spectrometers, Detectors and Associated Equipment, vol. 594, no. 2, pp. 215-219, 2008.

[4] J. Du and L. Kokou, "Europium environment and clustering in europium doped silica and sodium silicate glasses," Journal of Non-Crystalline Solids, vol. 357, no. 11-13, pp. 2235-2240, 2011.

[5] M.-L. Brandily-Anne, J. Lumeau, L. Glebova, and L. B. Glebov, "Specific absorption spectra of cerium in multicomponent silicate glasses," Journal of Non-Crystalline Solids, vol. 356, no. 44-49, pp. 2337-2343, 2010.

[6] W. F. Lim, K. Y. Cheong, Z. Lockman, F. A. Jasni, and H. J. Quah, "Effects of post-deposition annealing on $\mathrm{CeO}_{2}$ gate prepared by metal-organic decomposition (MOD) method on $4 \mathrm{H}-\mathrm{SiC}$," Materials Science Forum, vol. 645-648, pp. 837-840, 2010.

[7] W. F. Lim and K. Y. Cheong, "Study of molar ratio on the characteristics of metal-organic decomposed LaxCel-xOz film as a metal reactive oxide on Si substrate," Journal of Alloys and Compounds, vol. 581, pp. 793-800, 2013.

[8] H. J. Quah, K. Y. Cheong, Z. Hassan, and Z. Lockman, "Investigation of forming-gas annealed $\mathrm{CeO}_{2}$ thin film on $\mathrm{GaN}$," Journal of Materials Science: Materials in Electronics, vol. 22, no. 6, pp. 583-591, 2011.

[9] W. F. Lim and K. Y. Cheong, "Influence of post-deposition annealing in oxygen ambient on metal-organic decomposed $\mathrm{CeO}_{2}$ film spin coated on $4 \mathrm{H}-\mathrm{SiC}$," Journal of Materials Science: Materials in Electronics, vol. 23, no. 1, pp. 257-266, 2012.

[10] W. E. Lee, M. I. Ojovan, M. C. Stennett, and N. C. Hyatt, "Immobilisation of radioactive waste in glasses, glass composite materials and ceramics," Advances in Applied Ceramics, vol. 105, no. 1, pp. 3-12, 2006.

[11] J. M. Juoi, M. I. Ojovan, and W. E. Lee, "Microstructure and leaching durability of glass composite wasteforms for spent clinoptilolite immobilisation," Journal of Nuclear Materials, vol. 372, no. 2-3, pp. 358-366, 2008.

[12] W. Kaewwiset, K. Thamaphat, J. Kaewkhao, and P. Limsuwan, "ER ${ }^{3+}$-doped soda-lime silicate glass: artificial pink gemstone," The American Journal of Applied Sciences, vol. 9, no. 11, pp. 17691775, 2012.

[13] T. H. Cho and H. J. Chang, "Preparation and characterizations of $\mathrm{Zn}_{2} \mathrm{SiO}_{4}$ :mn green phosphors," Ceramics International, vol. 29, no. 6, pp. 611-618, 2003.

[14] E. Ozel, H. Yurdakul, S. Turan, M. Ardit, G. Cruciani, and M. Dondi, "Co-doped willemite ceramic pigments: technological behaviour, crystal structure and optical properties," Journal of the European Ceramic Society, vol. 30, no. 16, pp. 3319-3329, 2010.

[15] Y. Guo, H. Ohsato, and K.-I. Kakimoto, "Characterization and dielectric behavior of willemite and $\mathrm{TiO}_{2}$-doped willemite ceramics at millimeter-wave frequency," Journal of the European Ceramic Society, vol. 26, no. 10-11, pp. 1827-1830, 2006.

[16] E. F. Chillcce, I. O. Mazali, O. L. Alves, and L. C. Barbosa, "Optical and physical properties of $\mathrm{Er}^{3+}$-doped oxy-fluoride tellurite glasses," Optical Materials, vol. 33, no. 3, pp. 389-396, 2011.

[17] Q. Lu, P. Wang, and J. Li, "Structure and luminescence properties of $\mathrm{Mn}$-doped $\mathrm{Zn}_{2} \mathrm{SiO}_{4}$ prepared with extracted mesoporous silica," Materials Research Bulletin, vol. 46, no. 6, pp. 791-795, 2011.

[18] H. P. Rooksby and A. H. Keag, "The effect of nucleation catalysts on crystallization of aluminosilicate," Transactions of the Faraday Society, vol. 37, pp. 308-311, 1941.

[19] F. Marumo and Y. Syono, "Effects of soda-lime-silica waste glass on transition of $\mathrm{Er}^{3+}$ formation kinetics and micro-structures development in vitreous ceramics," Acta Crystallographica Section B, vol. 27, pp. 1868-1870, 1971.

[20] M. Takesue, H. Hayashi, and R. L. Smith Jr., "Thermal and chemical methods for producing zinc silicate (willemite): a review," Progress in Crystal Growth and Characterization of Materials, vol. 55, no. 3-4, pp. 98-124, 2009.

[21] A. Shaim, M. Et-Tabirou, L. Montagne, and G. Palavit, "Role of bismuth and titanium in $\mathrm{Na}_{2} \mathrm{O}-\mathrm{Bi}_{2} \mathrm{O}_{3}-\mathrm{TiO}_{2}-\mathrm{P}_{2} \mathrm{O}_{5}$ glasses and a model of structural units," Materials Research Bulletin, vol. 37, no. 15, pp. 2459-2466, 2002.

[22] C. L. Kanth, B. V. Raghavaiah, B. A. Rao, and N. Veeraiah, "Spectroscopic investigations on $\mathrm{ZnF}_{2}-\mathrm{MO}-\mathrm{TeO}_{2}(\mathrm{MO}=\mathrm{ZnO}, \mathrm{CdO}$ and $\mathrm{PbO}$ ) glasses doped with chromium ions," Journal of Quantitative Spectroscopy and Radiative Transfer, vol. 90, no. 1, pp. 97-113, 2005.

[23] Q. Chen, M. Ferraris, D. Milanese, Y. Menke, E. Monchiero, and G. Perrone, "Novel Er-doped $\mathrm{PbO}$ and $\mathrm{B}_{2} \mathrm{O}_{3}$ based glasses: investigation of quantum efficiency and non-radiative transition probability for $1.5 \mu \mathrm{m}$ broadband emission fluorescence," Journal of Non-Crystalline Solids, vol. 324, no. 1-2, pp. 12-20, 2003.

[24] R. Iordanova, Y. Dimitriev, V. Dimitrov, S. Kassabov, and D. Klissurski, "Glass formation and structure in the $\mathrm{V}_{2} \mathrm{O}_{5}-\mathrm{Bi}_{2} \mathrm{O}_{3}$ $\mathrm{Fe}_{2} \mathrm{O}_{3}$ glasses," Journal of Non-Crystalline Solids, vol. 204, no. 2, pp. 141-150, 1996.

[25] G. L. J. Trettenhahn, G. E. Nauer, and A. Neckel, "Vibrational spectroscopy on the $\mathrm{PbO}-\mathrm{PbSO}_{4}$ system and some related compounds. Part 1. Fundamentals, infrared and raman spectroscopy," Vibrational Spectroscopy, vol. 5, no. 1, pp. 85-100, 1993.

[26] C.-C. Lin and P. Shen, "Sol-gel synthesis of zinc orthosilicate," Journal of Non-Crystalline Solids, vol. 171, no. 3, pp. 281-289, 1994.

[27] M. R. Ahsan and M. G. Mortuza, "Infrared spectra of $\mathrm{xCaO}(1-\mathrm{x}-$ z) $\mathrm{SiO}_{2} \mathrm{zP}_{2} \mathrm{O}_{5}$ glasses," Journal of Non-Crystalline Solids, vol. 351, no. 27-29, pp. 2333-2340, 2005.

[28] D. R. Bosomworth, H. Hayes, A. R. L. Spray, and G. D. Watkins, "Absorption of oxygen in silicon in the near and the far infrared," Proceedings of the Royal Society of London A: Mathematical and Physical Sciences, vol. 317, no. 1528, pp. 133$152,1970$.

[29] J. Lin, D. U. Sänger, M. Mennig, and K. Bärner, "Sol-gel deposition and characterization of $\mathrm{Mn}^{2+}$-doped silicate phosphor films," Thin Solid Films, vol. 360, no. 1-2, pp. 39-45, 2000.

[30] S. Rada, P. Pascuta, L. Rus, M. Rada, and E. Culea, "Spectroscopic properties and ab initio calculations on the structure of erbium-zinc-borate glasses and glass ceramics," Journal of NonCrystalline Solids, vol. 358, no. 1, pp. 30-35, 2012.

[31] G. T. Chandrappa, S. Ghosh, and K. C. Patil, "Synthesis of glassceramic," Journal of Materials Synthesis and Processing, vol. 7, pp. 273-282, 1999. 
[32] P. Taret, "Etude infra-rouge des orthosilicates et des orthogermanates Une nouvelle methode d'interprétation des spectres," Spectrochimica Acta, vol. 18, no. 3, pp. 467-483, 1962.

[33] R. P. S. Chakradhar, B. M. Nagabhushana, G. T. Chandrappa, K. P. Ramesh, and J. L. Rao, "Solution combustion derived nanocrystalline $\mathrm{Zn}_{2} \mathrm{SiO}_{4}$ :Mn phosphors: a spectroscopic view," Journal of Chemical Physics, vol. 121, no. 20, pp. 10250-10259, 2004.

[34] H. Dunken and R. H. Doremus, "Short time reactions of a $\mathrm{Na}_{2} \mathrm{O}-\mathrm{CaO}-\mathrm{SiO}_{2}$ glass with water and salt solutions," Journal of Non-Crystalline Solids, vol. 92, no. 1, pp. 61-72, 1987.

[35] A. M. Efimov, "The IR spectra of non-oxide glasses of various types: crucial differences and their origin," Journal of NonCrystalline Solids, vol. 213-214, pp. 205-214, 1997.

[36] G. Navarra, R. Boscaino, M. Leone, and B. Boizot, "Irradiation effects on the $\mathrm{OH}$-related infrared absorption band in synthetic wet silica," Journal of Non-Crystalline Solids, vol. 353, no. 5-7, pp. 555-558, 2007.

[37] S. R. Lukić, D. M. Petrović, M. D. Dramićanin, M. Mitrić, and L. Dačanin, "Optical and structural properties of $\mathrm{Zn}_{2} \mathrm{SiO}_{4}: \mathrm{Mn}^{2+}$ green phosphor nanoparticles obtained by a polymer-assisted sol-gel method," Scripta Materialia, vol. 58, no. 8, pp. 655-658, 2008.

[38] F. F. Bentley, L. D. Smithson, and A. L. Rozek, Infrared Spectra and Characteristic Frequencies $\sim 700-300 \mathrm{~cm}^{-1}$, Interscience Publishers, New York, NY, USA, 1968.

[39] V. Sivakumar, A. Lakshmanan, S. Kalpana, R. Sangeetha Rani, R. Satheesh Kumar, and M. T. Jose, "Low-temperature synthesis of $\mathrm{Zn}_{2} \mathrm{SiO}_{4}$ : $\mathrm{mn}$ green photoluminescence phosphor," Journal of Luminescence, vol. 132, no. 8, pp. 1917-1920, 2012.

[40] T. H. Cho and H. J. Chang, "Preparation and characterizations of $\mathrm{Zn}_{2} \mathrm{SiO}_{4}$ :Mn green phosphors," Ceramics International, vol. 29, no. 6, pp. 611-618, 2003. 

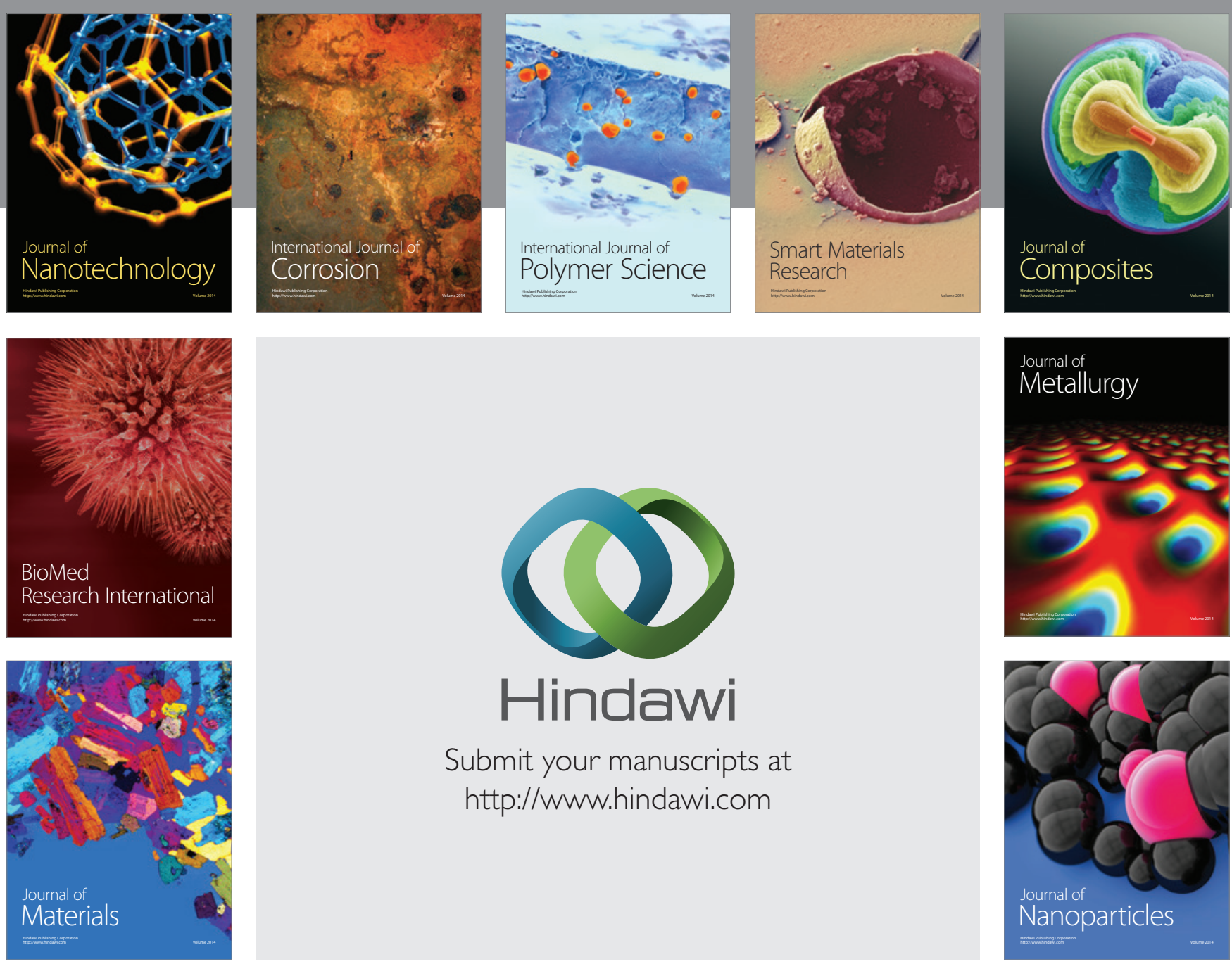

Submit your manuscripts at http://www.hindawi.com
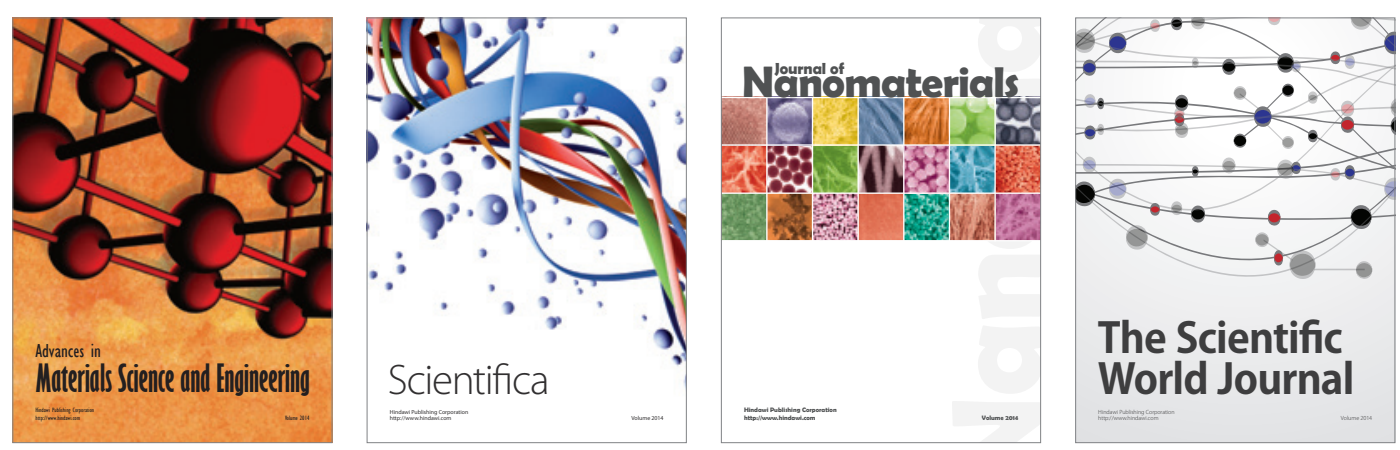

\section{The Scientific World Journal}
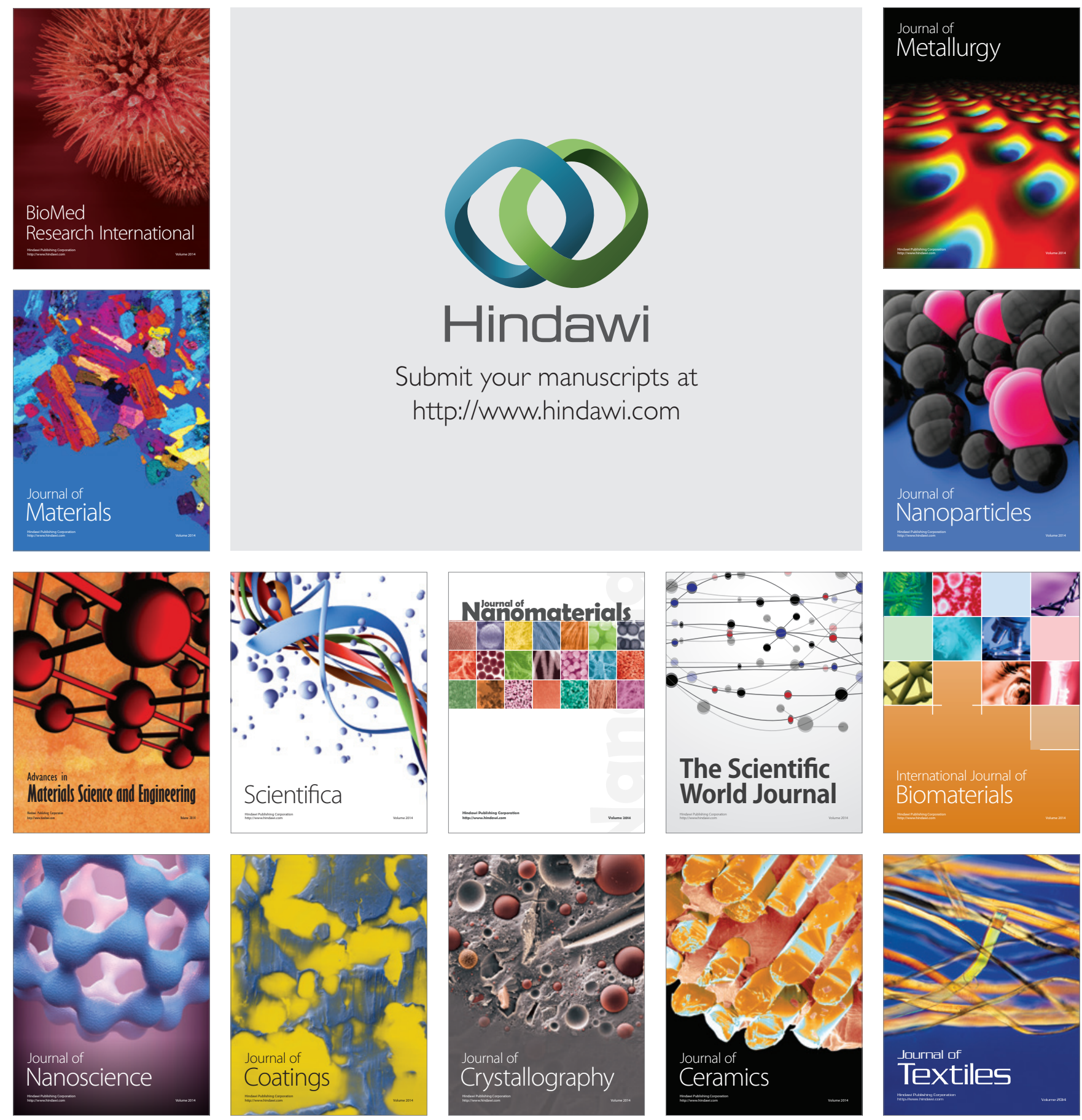